\title{
Análise do processamento da liga Ti30Ta visando aplicação biomédica
}

\author{
Analysis of processing of Ti30Ta alloy for biomedical applications \\ Análisis del proceso de fabricación de aleación de Ti30T \\ destinado a las aplicaciones biomédicas
}

Reginaldo Toshihiro KONATU

Kerolene Barboza da SILVA

Felipe da Silva BARROS

Ana Paula Rosifini ALVES CLARO

Departamento de Engenharia de Materiais, Faculdade de Engenharia de Guaratinguetá, UNESP-Univ Estadual Paulista, Guaratinguetá-SP, Brasil

\begin{abstract}
Resumo
Ligas de titânio são utilizadas para aplicações biomédicas devido às excelentes propriedades mecânicas, resistência à corrosão e biocompatibilidade. No presente trabalho foram analisadas a microestrutura e as propriedades mecânicas da liga Ti30Ta com diferentes níveis de compressão. A liga foi obtida por fundição em forno a arco voltaico com atmosfera inerte de argônio, homogeneizada, forjada e solubilizada. Para caracterização da liga Ti30Ta foram utilizadas técnicas de difração de raios-X (DRX) em temperatura ambiente e com aquecimento, calorimetria diferencial de varredura (DSC), microscopia eletrônica de transmissão (TEM) e compressão. As amostras deformadas em 19\%, 22\% e 44\% foram avaliadas usando as técnicas de DRX, microscopia óptica e microdureza. A liga apresentou transformação alotrópica a uma temperatura próxima de $650{ }^{\circ} \mathrm{C}$ e microestrutura do tipo $\alpha$ ". A compressão resultou no cisalhamento da amostra de $44 \%$ e valores de dureza próximos para as demais amostras analisadas.
\end{abstract}

Descritores: Ligas; Titânio; Propriedades Físicas e Químicas; Difração de Raios-X.

\begin{abstract}
Titanium and its alloys have been used for biomedical applications due their excellent mechanical properties, high corrosion resistance and biocompatibility. In this work, the microstructure and mechanical proprieties of Ti30Ta with different levels of compression were analyzed. Alloy were obtained in a arc melting furnace in an argon atmosphere, homogenized, cold worked by swaging and treated. The alloy was evaluated by X-ray diffraction (XRD), Heat treatment X ray diffraction (HTXRD) and differential scanning calorimetrical (DSC), transmission electron microscopy (TEM), and compression test with different deformations. The samples were deformed at reduction ratios of $19 \%, 22 \%$ and $44 \%$. After this deformation, its microstructure were evaluated by optical microscopy, X-ray diffraction (XRD) and micro hardness in each condition. The alloy show a allotropic transformation at $650{ }^{\circ} \mathrm{C}$, and $\alpha^{\prime \prime}$ microstructure. The compression resulted in the shear of the sample with $44 \%$ and near microhardness values for the other samples.
\end{abstract}

Descriptors: Alloys; Titanium; Physical and Chemical Properties; X-Ray Diffraction.

\section{Resumen}

Las aleaciones de titanio se usan para aplicaciones biomédicas debido a sus excelentes propiedades mecánicas, resistencia a la corrosión y biocompatibilidad. En este estudio, se analizaron las microestructuras y propiedades mecánicas de la aleación Ti30Ta a diferentes niveles de compresión. La aleación se obtuvo usando un horno de fusión de arco bajo una atmósfera inerte de argón, donde las muestras fueron homogenizadas, refrigeradas y solubilizadas. Para caracterizar la aleación Ti30Ta fueron utilizadas técnicas de difracción de rayos X (DRX) a temperatura ambiente y con calentamiento, calorimetría diferencial de barrido (DSC), microscopía electrónica de transmisión (TEM) y prueba de compresión con diferentes deformaciones. Las muestras fueron deformadas en radios de reducción de 19\%, 22\% y 44\%. Después de esta deformación, la microestructura fue evaluada por microscopia óptica, DRX y microdureza en cada condición. La aleación mostró transformación alotrópica a $650{ }^{\circ} \mathrm{C}$ y microestructura de tipo $\alpha$ ". La compresión resultó en el cizallamiento del $44 \%$ de las muestras y valores de microdureza cercanos para las otras muestras.

Descriptores: Aleaciones; Titanio; Propiedades Físicas y Químicas; Difracción de Rayos X. 


\section{INTRODUÇÃO}

A artroplastia total de quadril consiste na substituição ou troca da articulação do quadril. Pode ser empregada quando as funções são comprometidas devido à falha nas articulações ocasionadas por doenças como artroses, necroses e artrites e fraturas, associadas ao envelhecimento da população. Outra razão para essas cirurgias são as fraturas devido a quedas e acidentes ${ }^{1}$. Dessa forma, a utilização de implantes cresceu substancialmente nos últimos anos sendo que estudos recentes mostram que são colocados aproximadamente 1,5 milhão de implantes de quadril e 250 mil implantes de joelho por $\mathrm{ano}^{2}$, o que torna crucial o desenvolvimento de novos biomateriais.

As ligas CoCrMo, as ligas de titânio e o aço inoxidável 316 L são os biomateriais metálicos empregados para estas aplicações devido aos esforços associados a essa função. O módulo de elasticidade das ligas $\mathrm{CoCr}$ (240 GPa) e do aço inoxidável (210 GPa) é superior ao do osso (30 $\mathrm{GPa})$ o que ocasiona transferência de tensão insuficiente podendo causar reabsorção óssea ou falha do implante após alguns anos de uso. Dessa forma, a seleção de titânio e suas ligas para essas aplicações ocorre devido a seu módulo mais baixo (55 a $100 \mathrm{GPa}$ ) quando comparado a esses materiais além de baixa densidade, biocompatibilidade e elevada resistência à corrosão ${ }^{3}$.

O titânio comercialmente puro (cp) e a liga Ti6Al4V foram usados inicialmente em aplicações militares e aeronáuticas. Sua aplicação na área biomédica ocorreu a partir da década de 1960, com a liga Ti6Al4V substituindo gradualmente o titânio cp devido à elevada resistência mecânica. No entanto, sua utilização em longo prazo é contestada devido à citotoxicidade atribuída a presença do vanádio e alumínio o que tem levado ao estudo de ligas alternativas desde a década de 1990 4,5. Dessa forma, a adição de elementos de liga que proporcionem menor módulo de elasticidade ao titânio $\mathrm{cp}$, associado à ausência de citotoxicidade com excelente resposta do hospedeiro ainda é uma preocupação constante nos estudos de materiais para aplicações biomédicas.

Estudos realizados na década de noventa mostraram a viabilidade do emprego do tântalo em aplicações odontológicas e biomédicas, na fabricação de coroas metálicas devido a sua excelente adesão com cerâmicas e também devido a sua biocompatibilidade. As excelentes propriedades individuais desse elemento levaram ao estudo de ligas do sistema binário Ti-Ta ${ }^{6,7}$. $\mathrm{O}$ efeito do conteúdo de tântalo sobre o módulo de elasticidade dinâmico foi avaliado por diversos autores que concluíram que o teor de tântalo influenciou significativamente os resultados, sendo que as ligas Ti30Ta e Ti-70Ta exibiam os menores valores de módulo de elasticidades associados à melhor combinação de elevada resistência/baixo módulo, comparadas às outras composições avaliadas ${ }^{8}$. Desde então pesquisas foram dedicadas para avaliar a viabilidade do emprego dessas ligas a partir da modificação de suas propriedades de volume e superfície.

As ligas de titânio são amplamente usadas devido às propriedades que podem ser alcançadas a partir da manipulação dos elementos de liga e da microestrutura por meio de tratamentos térmicos e mecânicos. A manipulação destas diferentes microestruturas leva a diferentes combinações de propriedades e por isso é importante entender a relação entre a cristalografia e a morfologia de vários componentes microestruturais.

Além da microestrutura e propriedades mecânicas os processos de deformação envolvendo essas ligas são importantes para o seu desenvolvimento. Geralmente, quando a liga é deformada a temperatura ambiente, os mecanismos de deformação dependem mais dos elementos de liga do que da taxa de deformação. Estes mecanismos incluem escorregamento de discordâncias, nucleação e tensão induzem a formação da fase martensita 9 .

Dessa forma, o estudo das propriedades da liga Ti30Ta se tornou objeto desta pesquisa, cujo objetivo principal foi caracterizar as propriedades de volume da liga Ti30Ta de tal forma que fosse possível a sua utilização como biomaterial a partir da modificação de propriedades de superfície.

\section{MATERIAL E MÉTODO}

\section{- PROCESSAMENTO DA LIGA}

A liga Ti30Ta foi obtida à partir dos metais comercialmente puros, titânio (grau 2) e tântalo $(99.99 \%)$ em forno a arco voltaico com atmosfera inerte (gás argônio). Cada botão foi refundido cerca de 10 vezes com o objetivo de homogeneizar a liga. O lingote foi submetido a um tratamento térmico de homogeneização à vácuo a $1000{ }^{\circ} \mathrm{C}$ por 24 horas. Para facilitar o processo de forjamento, a liga foi submetida a um tratamento térmico de solubilização para estabilizar a fase $\alpha$ " a $950{ }^{\circ} \mathrm{C}$ por 2 horas. Os tarugos foram obtidos por forjamento rotativo (velocidade de rotação 1700 rpm) e solubilizados novamente a fim de eliminar tensões residuais.

- CARACTERIZAÇÃo DA LIGA EXPERIMENTAL Ti30Ta -Microscopia Eletrônica de Transmissão

Uma amostra com espessura de 0,2 $\mathrm{mm}$ teve as duas faces lixadas por deslizamento circular com lixas com granulometria 320, 1200, 2000 e polidas com sílica coloidal em suspensão $0.5 \mu \mathrm{m}$ até espessura próxima a 0,1 mm. A amostra foi enviada ao laboratório de caracterização estrutural (LCE) na Universidade Federal de São Carlos (UFSCar) para que o afinamento fosse continuado com a utilização do Ion Bean, plasma usado para retirar camadas finas do material, até que fossem 
atingidas as dimensões necessárias para a análise em microscópio eletrônico de transmissão da FEI, modelo Tecnai.

\section{- DSC (Calorimetria Diferencial de Varredura)}

Uma pequena amostra da liga Ti30Ta foi avaliada em forno tubular aquecido a $1000{ }^{\circ} \mathrm{C}$ com fluxo de gás argônio e resfriado até $100{ }^{\circ} \mathrm{C}$. Foram empregado cadinho de platina contendo a amostra de estudo e o cadinho de referência vazio. A análise por DSC foi realizada na Faculdade de Engenharia Mecânica (Unicamp).

\section{- Difração de Raios-X com Aquecimento}

A avaliação por difração de raios-X com aquecimento foi realizada em um difratômetro (X'Pert Pro, Panalytical) da Faculdade de Engenharia Mecânica (Unicamp). Uma amostra com $1 \mathrm{~mm}$ de espessura foi temperada e lixada usando lixas com granulometria de 220 a 1500 e então submetida à análise de composição das fases usando radiação $\mathrm{Cu} \mathrm{K \alpha}$, operando a $40 \mathrm{kV}$ com corrente de $30 \mathrm{~mA}$ a uma taxa de aquecimento de $2^{\circ} \mathrm{C} / \mathrm{min}$.

\section{- ENSAIO DE COMPRESSÃO A FRIO}

A norma da ASTM E9-09 foi utilizada para definir as dimensões do corpo de prova para o ensaio de compressão em função das dimensões do material obtido após a fusão e forjamento. Os corpos de prova foram usinados com $10 \mathrm{~mm}$ de diâmetro e $20 \mathrm{~mm}$ de comprimento. A fim de avaliar a forjabilidade da liga estes foram deformados mecanicamente a frio por compressão com três níveis de deformação diferentes (19\%, 22\% e 44\%), analisando como o material se comporta em relação ao grau de deformação imposto até o seu cisalhamento (44\%).

\section{- CARACTERIZAÇÃO MICROESTRUTURAL \\ -Fotoelasticidade}

Durante o teste de compressão à frio foi empregado o sistema de análise por fotoelasticidade. Simultaneamente a deformação das amostras foi examinada a distribuição das tensões por meio de um polaroscópio circular de reflexão (PhotoStress Plus, Vishay). Os corpos de prova foram recobertos por resina fotoelástica, fixada por meio de um adesivo reflexivo. Desta forma as deformações causadas na liga foram transmitidas à resina fotoelástica e os fenômenos óticos permitiram a visualização dos locais de concentração de tensão.

\section{- Microscopia Óptica}

Os corpos de prova comprimidos foram cortados longitudinal e transversalmente para a obtenção das amostras de caracterização que foram lixadas manualmente com lixas de granulometria entre 100 e 1500 seguido da limpeza em ultrassom por 5 minutos. As superfícies foram polidas com sílica coloidal em suspensão $0.5 \mu \mathrm{m}$ e ácido oxálico $5 \%$. O ataque químico foi realizado empregado uma das variações do reagente Kroll composto por $5 \% \mathrm{HF}, 10 \% \mathrm{HNO}_{3}, 85 \% \mathrm{H}_{2} \mathrm{O}$ por imersão durante 15 segundos, ao término as amostras foram lavadas em água corrente e secas. A microsestrutura da liga Ti30Ta foi analisada em microscópio óptico Epiphot (Nikon) e Axio Imager.Z2m (Zeiss) .

\section{- Difração de Raios-X}

A análise por difração de raios-X foi realizada empregando um difratômetro (Empyrean, PANalytical). As fases presentes na liga experimental Ti30Ta foram examinadas utilizando os seguintes parâmetros de operação: potência de $40 \mathrm{kV}$ e corrente de $30 \mathrm{~mA}$, comprimento de onda do $\mathrm{CuK} \alpha$, varredura entre os ângulos $30^{\circ}$ e $90^{\circ}$, com velocidade angular de varredura de $0,2 \%$ segundo em temperatura ambiente.

\section{- CARACTERIZAÇÃo MECÃNICA \\ -Microdureza}

A medida da microdureza Vickers da liga Ti30Ta foi realizada com uma carga de 50 gramas durante 15 segundos com auxílio de um microdurômetro (HMV 2t, Shimadzu).

\section{RESULTADOS E DISCUSSÃO}

A análise por difração de raios-X da liga Ti30Ta, Figura 1, confirmou a presença da fase $\alpha$ ". Esses resultados também foram verificados em estudos realizados para o sistema Ti-Ta por Zhou et al. ${ }^{8}$. De acordo com esses autores a formação da martensita em ligas Ti-Ta depende tanto do conteúdo de tântalo como da taxa de resfriamento. Quando resfriada rapidamente a partir do campo $\beta$ a $950{ }^{\circ} \mathrm{C}$ por uma hora as ligas Ti-Ta com teores de tântalo de 30 a $50 \%$ exibem estrutura $\alpha "{ }^{8}$.

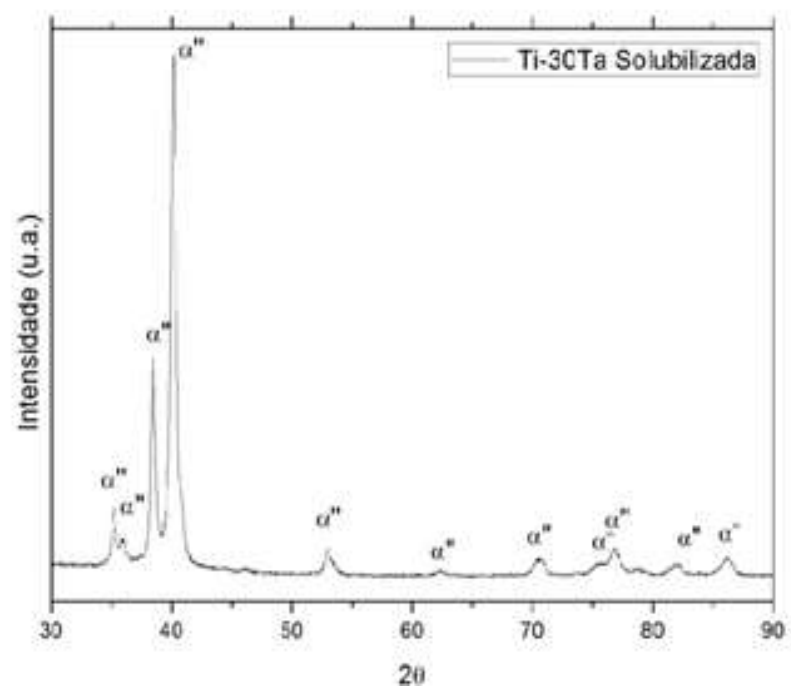

Figura 1 Espectro de difração de raios-X da liga Ti30Ta

A Figura 2 possibilita avaliar a curva obtida por DSC da liga experimental Ti30Ta. Os picos exotérmicos e endotérmicos foram adotados para cima e para baixo, respectivamente. A curva exibe uma variação exotérmica, com pico próximo de $650{ }^{\circ} \mathrm{C}$. O pico exotérmico está relacionado com a decomposição de $\alpha "$ para as fases $\alpha$ e $\beta$. Para o titânio cp a fase $\beta$ é estável entre 800 e $1000{ }^{\circ} \mathrm{C}$ o que indica que adição de tântalo levou a uma estabilidade dessa temperatura para patamares inferiores ${ }^{10,11}$.

A difração de raios- $X$ em temperaturas elevadas (HTRX) é fundamental para comprovar as análises realizadas em $\mathrm{DSC}^{12}$. A Figura 3 permite observar os 
espectros obtidos da amostra da liga Ti30Ta mediante variação de temperatura. A composição das fases sofre alterações acima de $700{ }^{\circ} \mathrm{C}$ com o aparecimento de novos picos que foram identificados como fase $\beta$ conforme constatado na análise DSC.

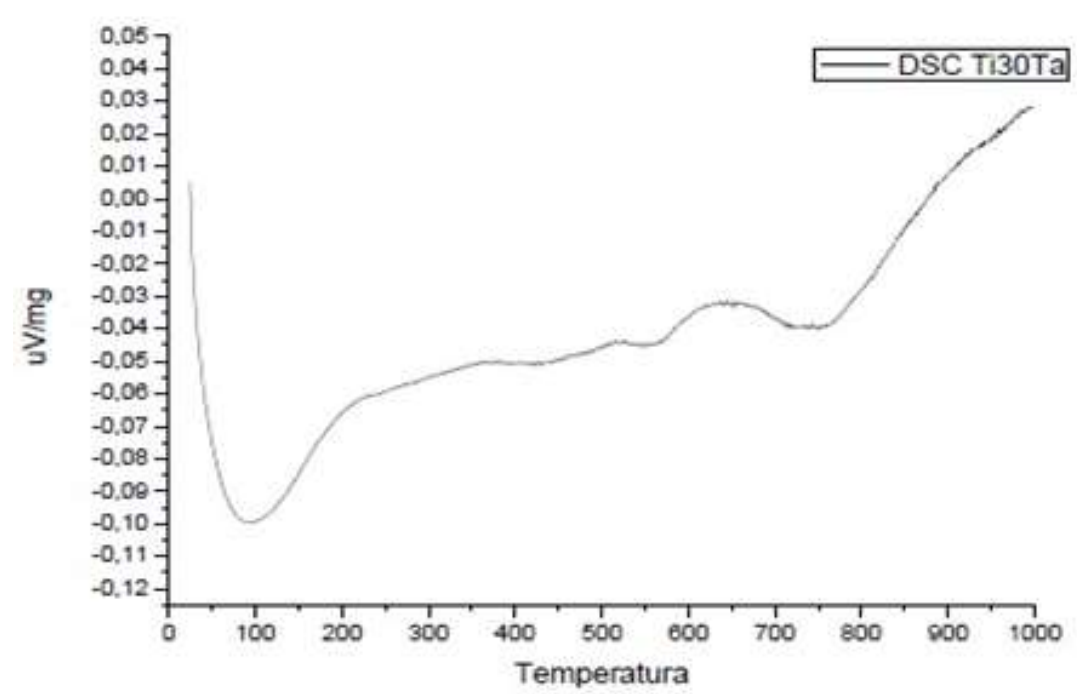

Figura 2. Curva obtida após análise térmica DSC da liga Ti30Ta

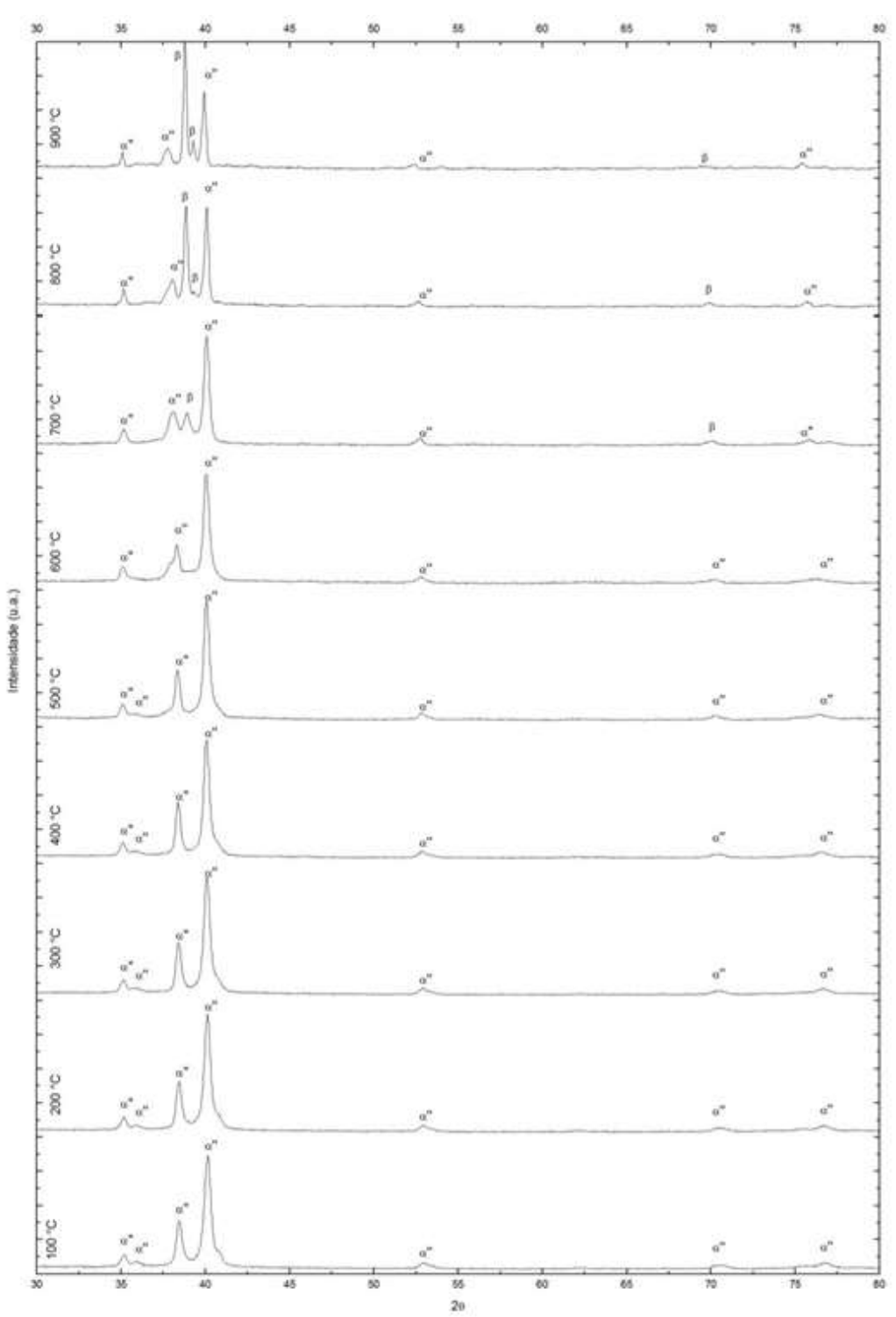

Figura 3. Espectro de difração de raios-X com aquecimento

A fase metaestável $\omega$ pode precipitar em ligas que passam por um tratamento de deformação mecânica ${ }^{13}$. Como a presença da fase hexagonal ômega não é registrado nas análises por difração de raios $\mathrm{X}$ devido as suas dimensões e quantidades muito reduzidas, a microscopia eletrônica de transmissão (TEM) foi realizada com o intuito de verificar se o forjamento rotativo poderia induzir a precipitação da fase $\omega$ na liga Ti30Ta.

A presença da fase $\omega$ (Figura 5) pode ser explicada pela realização do forjamento rotativo, porém, devido à quantidade encontrada durante a análise, existe a possibilidade de que o processo de preparação da amostra tenha induzido a formação da fase $\omega$ nesta quantidade. Ficando inconclusiva a presença desta fase, sendo necessárias mais análises para confirmar a presença da fase $\omega$.

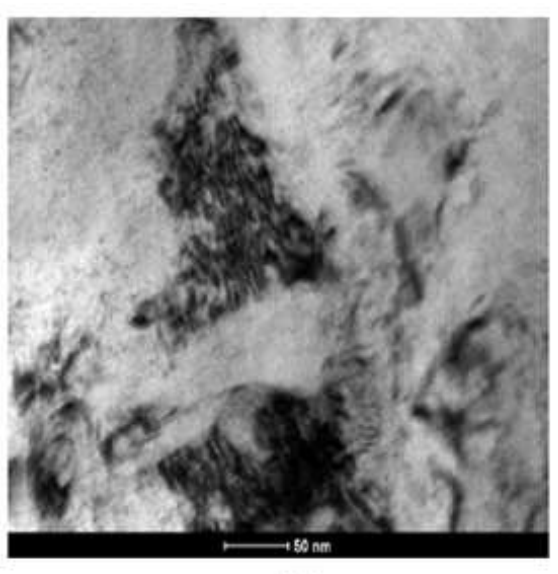

(a)

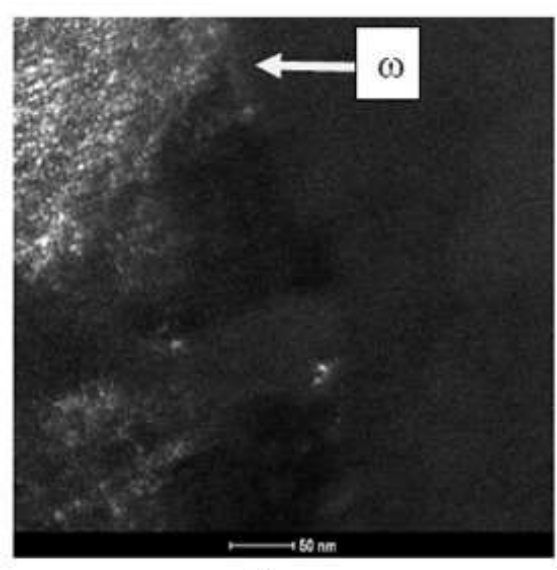

Figura 5. (a) Microscopia Eletrônica de Transmissão (Campo Claro) (b) Fase Omega

A sequência de imagens da Figura 6 permite observar a distribuição de tensões devida às cargas crescentes de compressão, de acordo com os planos de deslizamento principal da liga Ti30Ta.

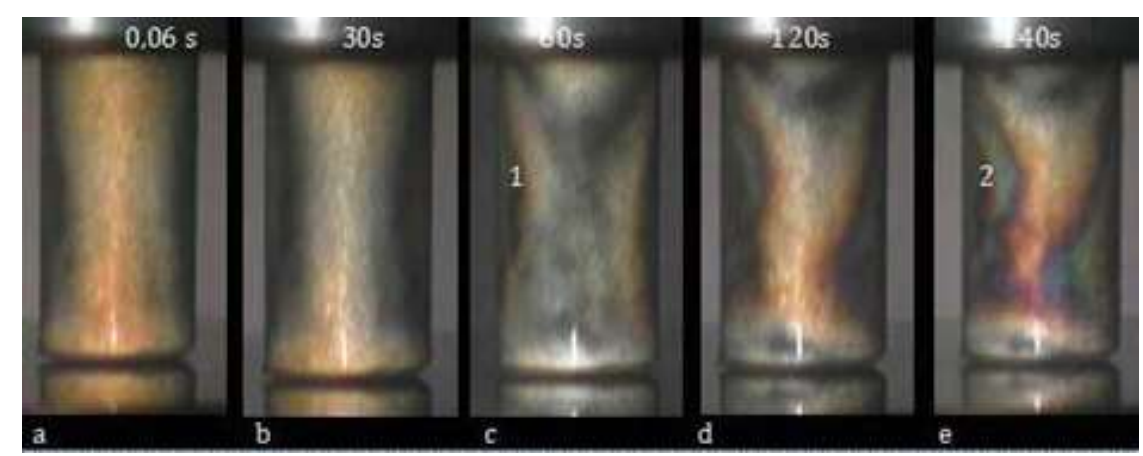

Figura 6. Sequência de imagens da distribuição de tensões decorrente de ensaio de compressão

As ordens de franjas isocromáticas indicam as magnitudes das tensões e os locais onde se concentram. É possível visualizar na Figura 6 (c) a formação de 1 ordem de franja (transição vermelho-azul) decorrente do carregamento e na Figura 6 (e) que o carregamento resultou em 2 ordens de franjas (transição vermelhoverde) localizadas próximas as bordas laterais do corpo de prova. A elevada resistência do material, comprovada pela necessidade de altas magnitudes de força para gerar as franjas isocromáticas, sugere a viabilidade do emprego da liga na fabricação dos implantes.

Conforme observado na Figura 7 as micrografias exibem a fase $\alpha$ ", evidenciada pela estrutura em forma de agulha, antes e após o ensaio de compressão. Para a amostra com $44 \%$ deformação nota-se que o esforço de compressão foi excessivo e levou ao cisalhamento do corpo de prova, enquanto no restante das amostras 
deformadas observou-se que o valores de dureza se mantiveram sem grandes modificações.

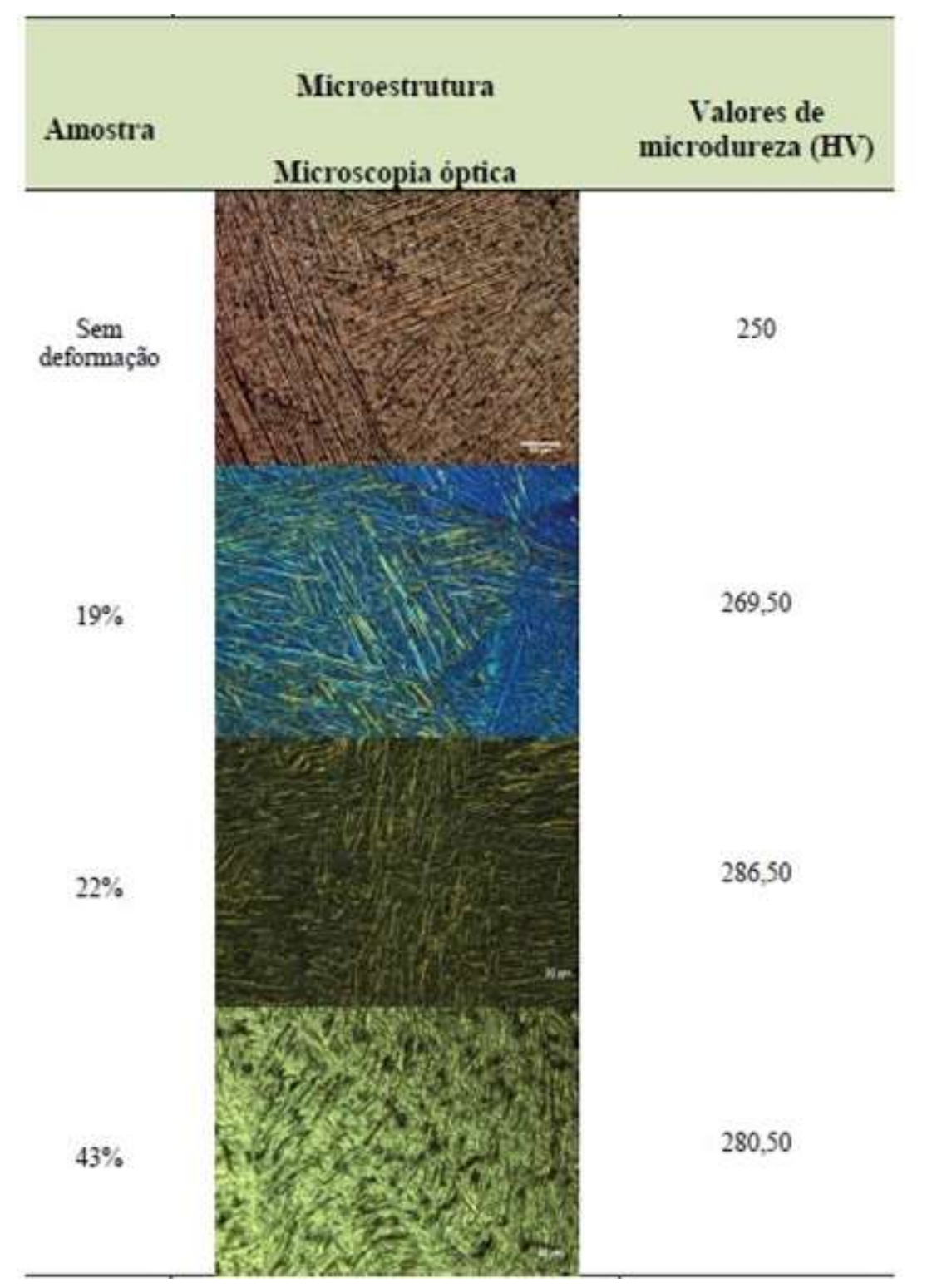

Figura 7. Micrografias obtidas após a deformação das amostras e valores de microdureza

As análises de difração de Raios- $X$ confirmaram a presença da fase $\alpha$ ". Tratamentos térmicos e mecânicos também podem estimular a formação de fase $\alpha^{\prime 14}$. O tratamento térmico de solubilização estabiliza a fase $\alpha$ " e oferece melhor conformação mecânica à frio que promove a formação de mais fases $\alpha^{\prime \prime}$, como foi percebido pelo espectros gerados pela difração de Raios-X, Figura 8.

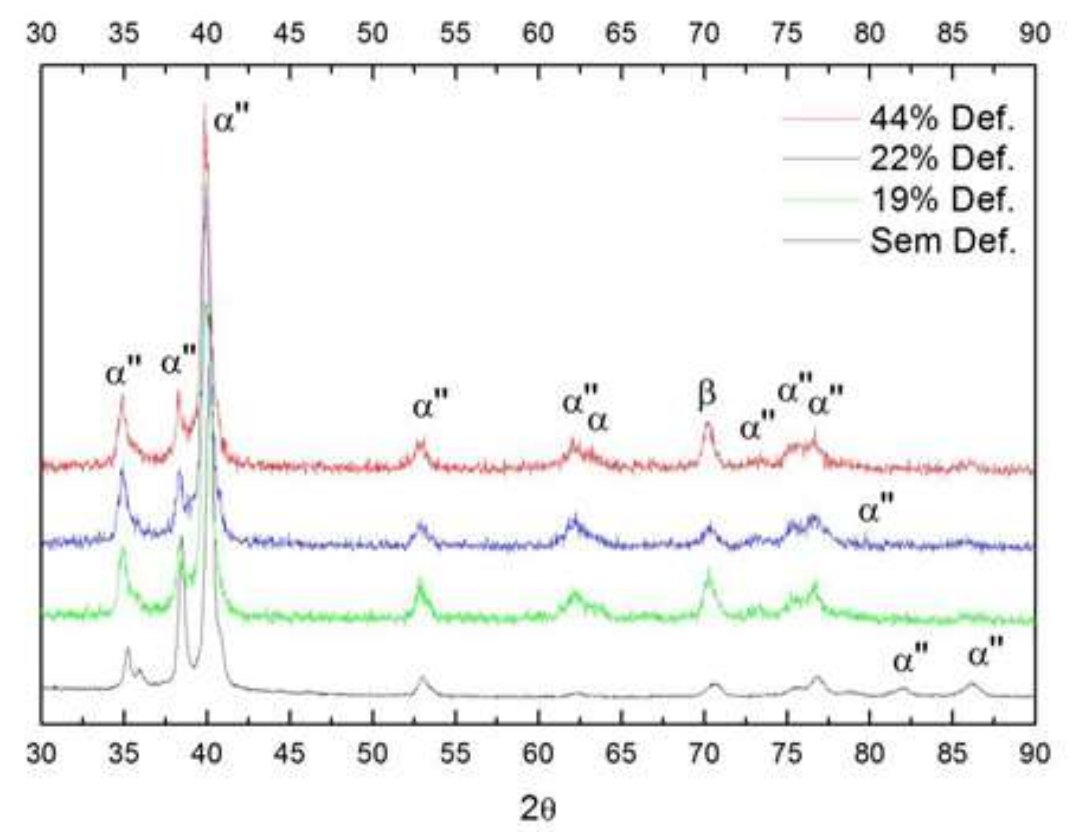

Figura 8. Espectros de difração de raios-X obtidas para as amostras após a deformação

\section{CONCLUSÃO}

A partir da realização dessa pesquisa foi possível concluir:

- O forjamento rotativo levou a presença da fase beta mantida após solubilização/têmpera.

- A realização dos ensaios de compressão não alterou as fases presentes no material, mantendo a fase $\alpha$ ", que em outros estudos mostrou ter módulo de elasticidade interessante para aplicações biomédicas.

- A presença da fase $\alpha^{\prime \prime}$ mostrou-se viável a deformação mecânica por compressão à frio até um nível de deformação específico, limitando seu tamanho ou exigindo um equipamento mais robusto. A liga se mostrou ideal para fabricação de próteses pequenas.

- A presença da fase $\omega$ é de difícil detecção pois o preparo a amostra da amostra pode ter induzido a formação desta fase, sendo necessários novos ensaios para confirmar esta fase.

\section{REFERÊNCIAS}

1. Simioni S. Manual da qualidade de implantes em artroplastia de quadril. Curitiba: Champagnat; 2012.

2. Nasab MB, Hassan MR, Sahari BB. Metallic Biomaterials of knee and hip - a review. Trends Biomater Artif Organs. 2010; 24(1):69-82.

3. Geetha M, Singh AK, Asokamani R, Gogia AK. Ti based biomaterials, the ultimate choice for orthopaedic implants - A review. Progress in Materials Science. 2009; 54:397-425.

4. Eisenbarth E, Velten D, Muller M, Thull R, BREME J. Biocompatibility of b-stabilizing elements of titanium alloys. Biomaterials. 2004; 25(26):5705-13.

5. Long M, Rack HJ. Titanium alloy in total joint replacement - a materials science perspective. Biomaterials. 1998; 19(18):1621-39.

6. Gibbesch B, Elssner G, Mader W, Fischmeister H. Ultrahigh Vacuum Diffusion Bonding of Metals to Ceramics. Proceedings of the International Forum on Structural Ceramics Joining: Ceramic Engineering and Science Proceedings. 2008; 10(11/12).

7. Prigent $\mathrm{H}$, Pellen-Mussi $\mathrm{P}$, Cathelineau $\mathrm{G}$, Nonnaure-Mallet M. Evaluation of the biocompatility of titanium-tantalum alloy versus titanium. J Biomed Mater Res. 1998; 39(2):200-6.

8. Zhou YL, Niinomi M, Akahori T. Decomposition of martensite $\alpha^{\prime \prime}$ during aging treatments and resulting mechanical properties of $\mathrm{Ti}-\mathrm{Ta}$ alloys. J Mater Sci Eng A. 2004; 384(1-2):92-101.

9. Wang $\mathrm{L}$, Lu $\mathrm{W}$, Qin J, Zhang $\mathrm{F}$, Zhang $\mathrm{D}$. Microstructure and mechanical properties of coldrolled TiNbTaZr biomedical $\beta$ titanium alloy. J Mater Sci Eng A. 2008; 490(1-2):421-6. 
10. Mantani Y, Takemoto Y, Hida M Sakakibara A, Tajima M. Phase Transformation of Martensite Structure by Aging in Ti-8 mass\%Mo Alloy. Materials Transactions. 2004; 45(5):1629-34.

11. Mantani Y, Tajima M, Phase transformation of quenched $\alpha^{\prime \prime}$ martensite by aging in Ti-Nb Alloys. J Mater Sci Eng A. 2006; 438-440:315-9.

12. Stroud RM, Kelton KF. High temperature $x$-ray and calorimetric studies of phase transformations in quasicrystalline Ti-Zr-Ni alloys. J Mater Res. 1997; 12(2):434-8.

13. Hickman BS. - The Formation of Omega Phase in titanium and zirconium alloys: a Review J Mater Sci. 1969; 4(6):554-63.

14. Lopes JFSC. Avaliação de processos de deformação plástica, recristalização e envelhecimento de ligas Ti$\mathrm{Nb}$ [dissertação]. Campinas: Universidade Estadual de Campinas - UNICAMP; 2010.

\section{CONFLITO DE INTERESSES}

Os autores declaram não haver conflitos de interesse.

\section{AUTOR PARA CORRESPONDÊNCIA}

Ana Paula Rosifini Alves Claro

rosifini@feg.unesp.br

Submetido em 18/05/2016 Aceito em 27/06/2016 